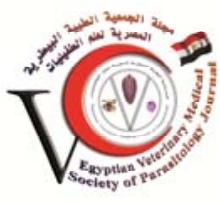

Original Article

\title{
The role of freshwater fishes in transmitting some zoonotic parasites with trial to treatment with Moringa aeloifera
}

Sahar ER Saba

Parasitology Department, Animal Health Research Institute, Dokki, Giza

\begin{abstract}
:
The incidence of encysted metacercaria (EMC) was investigated in 200 freshwater fish samples represented 100 from each of Clarias gariepinus and Cyprinus carpio. Fish were collected from River Nile resources at EL-Daqahlyia governorate. The total incidence of EMC in examining fish was $73.5 \%$, while in Clarias gariepinus and Cyprinus carpio were 86\% and 61\%, respectively. An artificial digestion technique for collection and identification of encysted metacercariae from investigating infected fish revealed that EMC is belonging to Prohemistominae in Clarias gariepinus and Heterophyidae in Cyprinus carpio. The experimental infection of puppies with isolated EMC from the studied freshwater fishes revealed the detection of four trematodes species: Prohemistomum vivax, Mesostephanus appendiculatus, Heterophyes heterophyes, Procervim varium. The pathological changes due to the effect of the developmental larval stages (EMC) and their adult zoonotic trematodes on their hosts were studied. Due to health hazards and impact of such these fish born zoonotic trematodes (FBZTs), this study focuses on the validation of the traditional use of Moringa oleifera derivatives for exterminate of intestinal helminths as the obtained result revealed that Moringa oleifera seed oil have higher anthelmintic activity than Moringa oleifera leaf extract.
\end{abstract}

Key words: EMC - Clarias gariepinus - Cyprinus carpio - anthelmintic activity- Moringa oleifera

\section{INTRODUCTION}

Egypt has large areas of fresh, brackish, and marine water bodies suitable for fishing. Moreover, the climatic conditions are optimum for fish farming, with high growth rates of the fish that are raised, which constitute a cheap source of animal protein for Egyptians (Oczkowski 2009). The World Health Organization (WHO) has estimated that the number of people currently infected with fish-borne trematodes exceed 18 million and many more are at risk (WHO, 1995). Fish- borne zoonotic trematodes (FBZTs) are among the most neglected tropical disease agents (WHO 2011). Despite the prevalence and high cost, FBZTs infections are poorly recognized by public health authorities and consumers alike. Plants are being used all over the world for the cure of countless disease conditions. Treatment of diseases using plants or their extracts is called as "Phytotherapy". It is sometimes also called as Herbalism, plant medicine and Herblore (Tabassam et al., 2014). Phytotherapy is considered under the category of Pharmacognosy, which studies medicines acquired from substances occurring in nature. The Egyptians considered an expert in the use of herbal remedies. Moringa oleifera, known as the "miracle tree", is greatly esteemed for its unique nutritional and medicinal value. Extracts from this plant have several pharmacological effects such as anthelmintic (Kamaraj and Abdul Rahuman 2011), anti-inflammatory (Chandrashekar et al. 2010), antimicrobial, anti-oxidant (Singh et al., 2012), hepato-protective, anti-glycemic and antidislipidemia effects (Mbikay 2012).

In view of the importance of these parasites, the present study was therefore designed to study the incidence and types of some encysted metacercariae (EMC) in examining fish. Conforming and identification of adult trematodes after experimentally infected puppies with detected EMC from inspecting fresh water fishes. In addition to the a meliorating role Moringa oleiferain as anthelmintic treatment plant. Clarify the histopathological changes induced by the Encysted metacercariae and adult stages.

\section{MAterials AND Methods}

Experimental animals:

Ten laboratory-reared puppies of 2 weeks old. It was fed and watered ad libitum and hygienically caged in suitable steel cages of isolation units in biosecurity animal building throughout the experimental period. The puppies were naive for parasite exposure based on the lack of any detectable parasite eggs as determined by daily fecal examination for 3 successive days before challenge. 


\section{Fish samples:}

Two hundred fish samples represented 100 from each of Clarias gariepinus and Cyprinus carpio fish were collected from River Nile resources at the EL-Daqahlyia governorate. The collected fish samples were identified and transferred in an icebox to the lab. as soon as possible and examined for the presence of encysted metacercariae (EMC).

\section{Collection of metacercariae:}

Initially fish samples were screened for the presence of EMC, macroscopically either by naked eye or by the magnifying hand lens. Microscopic examination by compression method in which snipes were taken from different parts of each fish. Each piece was compressed between two microscopic glass slides and examined microscopically for the presence of EMC (Elsheikha and Elshazly 2008a). Artificial digestion method (Nithikathkul and Wongsawad 2008) using acidified $1 \%$ pepsin solution (1 $\mathrm{ml}$ conc. hydrochloric acid, $1 \mathrm{~g}$ pepsin, $99 \mathrm{ml} 0.85 \%$ sodium chloride solution for $1-3$ hour at $37^{\circ} \mathrm{C}$ ) was used in case of infected fish in order to separate metacercariae. Different types of metacercariae were tentatively identified to species level based on the morphological details and being either singly or in groups (Elsheikha and Elshazly 2008a; Sohn et al., 2009).

\section{Tested drugs:}

Preparation of Moringa oleifera leaf extract according to Janani et al. (2013).

B. Moringa oleifera seed oil: purchased as a marketed product from a private seller produced by Ramona Cosmaceuticals Pvt. Ltd., Rajapalayam, Tamilnadu.

\section{Experimental design:}

In a trial to get the adults of the obtained microscopic then, treated with Moringa oleifera, EMC experimental infection of ten (two-week-old) puppies kept in a comfortable cage were supplied daily with the required feed and drinking water. Table 1 explains the assigned of puppies into two groups (Group $1 \& 2$ ). First group and $2^{\text {nd }}$ gp are sub-assigned into two subgroups each one consisting of a 2 puppies.

\section{Experimental infection:}

Each puppy of any tested group was experimentally infected by orally inoculated with $10 \mathrm{ml}$ saline containing about 500 viable EMC. Daily fecal samples from each infected puppy were examined by direct examination, and floatation, sedimentation techniques (Faust et al., 1976) for the demonstration of adult fluke's eggs.

\section{The groups of puppies were experimented as follow:- Group 1:}

The experimental infection of puppies was confirmed by shedding eggs in their feces (after about 7-10 days of infection). The infected puppies stayed until number of eggs in the feces began to decrease. All puppies were euthanized and necropsied for isolation and collection of adult trematodes as previously described (Sohn and Chai, 2005). The collected worms were fixed with $10 \%$ neutral buffered formalin under a cover glass pressure, stained with Semichon's acetocarmine and observed using a light microscope equipped with a micrometer (OSM-4, Olympus Co., Tokyo, Japan). All measurements are given in $\mu \mathrm{m}$ unless stated otherwise. Identification of different detected adult trematodes was done using key reference Yamaguti (1958). Samples were taken from the small intestines preserved in $10 \%$ formalin and prepared for histopathological examination.

\section{Group 2:}

The treatment regimens were started after 9 days of infection, which was confirmed by the presences of eggs in feces. Subgroup $2 b$ was treated with Moringa oleifera leaf

Table 1: Experimental design

\begin{tabular}{|c|c|c|c|}
\hline Groups & subgroup & Clarias gariepinus & Cyprinus carpio \\
\hline Group I (4 puppies) & Sub gp. 1a ( 2 puppies) & infected by 500 viable EMC & - \\
\hline $\begin{array}{l}\text { For collection and identifica- } \\
\text { tion of adult worms }\end{array}$ & Sub gp. 1b (2 puppies) & - & $\begin{array}{l}\text { infected by } 500 \\
\text { viable EMC }\end{array}$ \\
\hline Group II (6 puppies) & Sub gp. 2a (2 puppies) & infected by 500 viable EMC & - \\
\hline \multirow{3}{*}{$\begin{array}{l}\text { For comparative validation of } \\
\text { Moringa oleifera derivateives } \\
\text { anthelmintic activity. }\end{array}$} & Infected non treated, control positive & & \\
\hline & $\begin{array}{c}\text { Sub gp. } \mathbf{2 b} \text { ( } 2 \text { puppies) } \\
\text { Infected \& treated by Moringa oleifera leaf } \\
\text { extract. }\end{array}$ & infected by 500 viable EMC & - \\
\hline & $\begin{array}{c}\text { Sub gp. } \mathbf{2 c} \text { (2 puppies) } \\
\text { Infected \& treated by Moringa oleifera seed oil. }\end{array}$ & infected by 500 viable EMC & - \\
\hline
\end{tabular}


extract, which was given orally at a dose of $3 \mathrm{gm} / \mathrm{kg} \mathrm{BW} /$ day for 5 successive days, according to Alghabban (2014). Subgroup 2c was treated with Moringa oleifera seed oil, which was given orally in a dose of $3 \mathrm{ml} / \mathrm{kg}$ BW/day for 5 consecutive days according to Nilani et al. (2012).

In order to evaluate the efficacy of the tested drugs, according to Ammar (2007) the following was done:

\section{Parasitological parameters:}

Egg count per gram of feces (EPG).

Fecal samples were collected daily for detection of adult fluke's eggs. Egg count per gram of feces was done using the Mc-Master Slide (Jain, 2002).

Worm count recovered from the small intestine (WRR). All animal groups were euthanized, at the same time, after the end of drug regimens ( 15 days post infection). The whole small intestine of the euthanized puppies was taken and prepared for estimation of worm recovery and histopathological examination. The collected flukes were adjusted in $20 \mathrm{ml}$ saline and the number of adult worms was counted for each puppy in one $\mathrm{ml}$, replicated three times and got the average number.

\section{Histopathological examination:}

Small parts of muscles of naturally infected examined fishes and intestine of experimentally infected non treated (Subgroup 1a, 1b, 2a) and treated puppies (Subgroup 2b \& 2c) were taken and fixed in $10 \%$ neutral buffer formalin solution. The tissue was processed by conventional methods, sectioned at 4-6 $\mu$ thickness and stained with Haematoxylin and Eosin (Bancroft and Gamble 2013). Then examined microscopically to study the pathological changes due to the effect of the developmental larval stages (EMC) and their adult on their hosts.

\section{Drug efficacy:}

Calculation of drug efficacy or reduction percentage was done according to the equation:

$$
\text { Efficacy }=\frac{a-b}{a} \times 100
$$

\section{Where}

$\mathrm{a}=$ mean number of adult worms recovered from the intestine of infected non treated puppies (control positive).

$b=$ mean number of adult worms recovered from infected treated puppies.

\section{RESULTS}

Incidence of EMC in examining fish:

The total incidence of EMC in investigating fish was $73.5 \%$. The infection rate (86\%) was recorded in Clarias gariepinus while in Cyprinus carpio was $61 \%$ Table (2). In the present study three different EMC were recovered from examining fish. Clarias gariepinus harbored Prohemistominae, while Cyprinus carpio harboring to Heterophyidae.

Table 2: The incidence of EMC in examined fish Clarias gariepinus and Cyprinus carpi

\begin{tabular}{lccc}
\hline & $\begin{array}{c}\text { No. of } \\
\text { examined Fish }\end{array}$ & $\begin{array}{c}\text { No. of } \\
\text { infected Fish }\end{array}$ & $\%$ \\
\hline Clarias gariepinus & 100 & 86 & 86 \\
Cyprinus carpio & 100 & 61 & 61 \\
Total & 200 & 147 & 73.5 \\
\hline
\end{tabular}

Morphology of the detected encysted metacercariae:

Macroscopic examination of the detected EMC from the infected examined fish displayed deep dark color point (melanin pigment) on the skin varied in size. Microscopic examination of EMC revealed the following:

Metacercariae encountered in the muscles of Clarias gariepinus:

Prohemistomatid Metacercaria:

These measures $300-320$ by 310-345 $\mu$. They are spherical or subspherical, double walled, outer thick and inner hyaline and separated from the metacercaria by a potential space containing fluid in which the metacercaria was moving, pigmented granules and vacuoles were present in this space. Cysts were surrounded by a thick layer of infiltrating cells, the layer differed in thickness at different levels. The metacercaria was usually folded inside its cyst wall.

\section{Metacercariae encountered in the muscles of Cyprinus carpio:}

Heterophyid Metacercaria:

The cyst was globular to elliptical in shape, it measured 448 by $330 \mu$ It had two layers, the outer one was thin and transparent, but the inner layer was homogeneous in structure with bright bluish color with pigment granules distributed all over the body.

Identification of eggs in puppies' feces:

Prohemistomatid eggs:

The period of the first appearance of eggs in subgp. 1a, 2a, $2 b, 2 c$ puppies' feces ranged from the 10th day post infection. The eggs appeared large in size, measured 75$109 \times 50-77 \mu$, greenish yellow in color, operculated with thin shell $($ Fig $1, \mathrm{~A})$. 


\section{Heterophyid eggs:}

The period of the first appearance of eggs in subgp. $1 \mathrm{~b}$ puppies' feces ranged from the 8th to 9th day post infection. The eggs of heterophyids were minute measured $29 \times 16 \mu$, light brown in color, oval in shape, emboryonated with thick shell and having operculum.There was a knob at the posterior pole (Fig $1, B)$.

Table (3): Comparison between studied infected group 2 of puppies regarding EPG at different days of estimation.

The table shows that :

- Regarding the EPG at 10 days post infection and before treatment, there was no significant difference between the studied infected groups.

- EPG at 15 days post infection (5 day of treatment) was found to be significantly lower in puppies treated with Moringa oleifera seed oil than control +ve ones.

- The EPG was significantly lower in Subgp. 2b which treated with Moringa oleifera seed oil. Than subgp. 2a which treated with Moringa oleifera leave extract.

- At 18 days post infection (8 days of treatment), there were significant lower levels of EPG in treated subgp $2 \mathrm{~b}$ and $2 \mathrm{c}$ than control +ve subgp. $2 \mathrm{a}$.

- At 20 days post infection (10 day of treatment) there was complete disappearance of eggs in feces of Moringa oleifera seed oil treated puppies.

- There was significantly lower EPG with increase the duration post infection in all the studied infected groups.

\section{Identification of recovered adult trematodes:}

The recovered adult trematodes from experimental infection of puppies (subgp. 1a) revealed that 2 adult trematodes species belonging to; Family Cyathocotylidae,

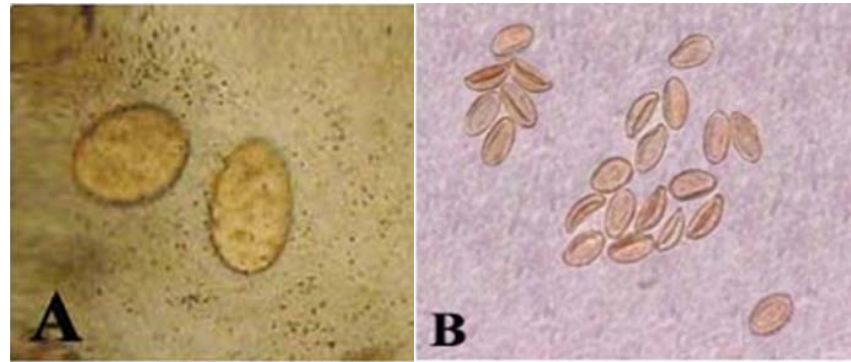

Figure 1: A) Prohemistomatid worm egg in feces of infected puppies (x400). B) Heterophyid worm egg in feces of infected puppies $(x 400)$

Prohemistomum vivax and Mesostephanus appendiculatus (Fig. 2 A \& B) while other 2 adult trematodes species were collected from the infected puppies of (subgp. 1b) belonging to; Family Heterophyidae, Heterophyes heterophyes and Procervim varium (Fig. 2 C \& D).

Worm recovery rate (WRR) and the efficacy of the drugs (Fig 3):

Table (4): Comparison between studied infected subgroups regarding worm recovery rate (WRR) and drug efficacy or
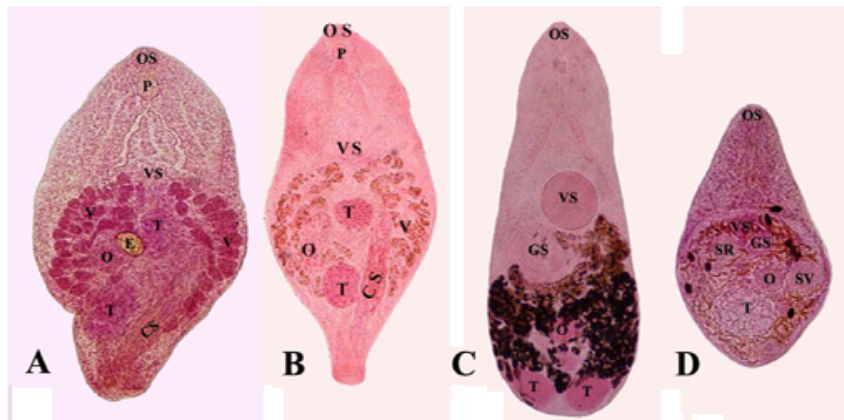

Figure 2: A) Prohemistomum vivax (x100), B) Mesostephanus appendiculatus (x100), C) Heterophyes heterophyes (x100), D) Procervim varium $(\mathrm{x} 100)$

OS: Oral sucker, VS: Ventral sucker, GS: Genital Sucker, T: Testes, O: Ovary, CS: Cirrus sac, V: Vitelline Follicles, SR: Seminal Recepticulum, SV: Seminal Vesicles, E: Egg

Table 3: Comparison of EPG (Egg counting per gram) at different days of estimation with detection of adult worms in infected treated puppies feces with subgp. 2a (positive control)

\begin{tabular}{|c|c|c|c|c|c|c|}
\hline \multirow[b]{2}{*}{ Day } & \multicolumn{2}{|c|}{$\begin{array}{c}\text { subgp. 2a } \\
\text { infected non-treated } \\
\text { (control positive) }\end{array}$} & \multicolumn{2}{|c|}{$\begin{array}{c}\text { subgp. } 2 \mathrm{~b} \\
\text { treat with Moringa oleifera } \\
\text { leaf extract }\end{array}$} & \multicolumn{2}{|c|}{$\begin{array}{c}\text { subgp. 2c } \\
\text { treat with Moringa oleifera } \\
\text { seed oil. }\end{array}$} \\
\hline & Eggs No. & Adult & Eggs No. & Adult & Eggs No. & Adult \\
\hline 9 day of infection & 170 & Absence & 168 & Absence & 174 & Absence \\
\hline $1^{\text {st }}$ day post treat (10 day of infection) & 172 & Absence & 130 & Absence & 134 & Absence \\
\hline 2nd day of treat & 174 & Absence & 132 & Absence & 130 & Present \\
\hline 3rd day of treat & 174 & Absence & 130 & Absence & 102 & Present \\
\hline 4th day of treat & 170 & Absence & 100 & Present & 60 & Present \\
\hline 5 th day of treat & 168 & Absence & 86 & Present & 10 & Present \\
\hline 6 th day of treat & 160 & Absence & 60 & Present & 6 & Present \\
\hline 7th day of treat & 156 & Absence & 20 & Present & 4 & Absence \\
\hline 8th day of treat & 150 & Absence & 18 & Present & - & Absence \\
\hline 9th day of treat & 100 & Absence & 4 & Absence & - & Absence \\
\hline 10th day of treat & 90 & Absence & - & Absence & - & Absence \\
\hline
\end{tabular}


reduction $\%$ the table shows that:-

- Regarding the WRR, there were significantly lower WRR in each of subgrp. $2 a$ and $2 b$ which treated with Moringa oleifera leave extract and Moringa oleifera seed oil respectively than control +ve one.

- The mean number of recovered worm was significantly lower in subgroup $2 b$ treated with Moringa oleifera seed oil than subgp. 2a treated with Moringa oleifera leave extract.

- There were significant difference in drug efficacy between Moringa oleifera leave extract and Moringa oleifera seed oil, the highest efficacy was in Moringa oleifera seed oil and the lowest was in Moringa oleifera leave extract.

\section{Pathological examination:}

The EMC are subspherical, double walled, outer thick and inner hyaline and separated from the metacercaria by a potential space containing fluid in which the metacercaria was moving, vacuoles and adipose tissues were present in this space. These are measuring $290-320$ by $300-340 \mu$ in size. The EMC were surrounded by a thick layer and it was usually folded inside its cyst wall (Fig. 4 A \& B). EMC between muscle fibers of fish, showing partially destruction of the parasite and surrounded by grayish, homogenous material, moderately thick fibrous tissue capsule and characteristic features were fine streaks of black coloration (melanin pigment) in the infected musculature (Fig. 4C). Intestine of infected puppy, showing adult worm of Heterophyes $s p$. in between intestinal villi reflect reaction in intestinal mucosa ranged between light to sever reaction, mainly sloughed intestinal mucosal epithelial lining can reach to partially replaced the villi (induced erosion in the mucosa), pressure atrophy of villi and sever hyperplasia of goblet cells with sever infiltration of propria submucosa by mononuclear inflammatory cells mainly and few eosinophils. (Fig. 4D),

Also, the mature adult worm of Prohemistomum sp. embedded between the villi of intestine and induced pressure atrophy in adjacent tissue. The epithelium of villi suffer extensive mucinous degeneration (increase number of goblet cells). The mucosa showed sever infiltration of leuckocyte (Fig. 4 E). In treated duodenum with Moringa oleifera show no adult worms, sign of decreasing of inflammatory reaction in intestine were observed characterized by decreasing in infiltration inflammatory cells with mostly intact epithelial lining but associated with few goblet cells hyperplasia (Fig. 4 F).
Table 4: Comparison between studies infected subgroups regarding worm recovery rate (WRR) and drug efficacy or reduction $\%$

\begin{tabular}{|c|c|c|c|}
\hline Data & $\begin{array}{l}\text { Control } \\
\text { +ve }\end{array}$ & $\begin{array}{l}\text { subgp. Ilb } \\
\text { puppies } \\
\text { treat } \\
\text { with } \\
\text { Moringa } \\
\text { oleifera } \\
\text { leaf extract }\end{array}$ & $\begin{array}{c}\text { subgp. Ilc } \\
\text { puppies } \\
\text { treat } \\
\text { with } \\
\text { Moringa } \\
\text { oleifera } \\
\text { seed oil }\end{array}$ \\
\hline & $\begin{array}{c}\text { Mean of } \\
\text { worm No. }\end{array}$ & $\begin{array}{c}\text { Mean of } \\
\text { worm No. }\end{array}$ & $\begin{array}{l}\text { Mean of } \\
\text { worm No. }\end{array}$ \\
\hline WRR & 101 & 18 & 4 \\
\hline $\begin{array}{l}\text { Drug } \\
\text { efficacy or } \\
\text { reduction \% }\end{array}$ & - & $82.10 \%$ & $96 \%$ \\
\hline
\end{tabular}

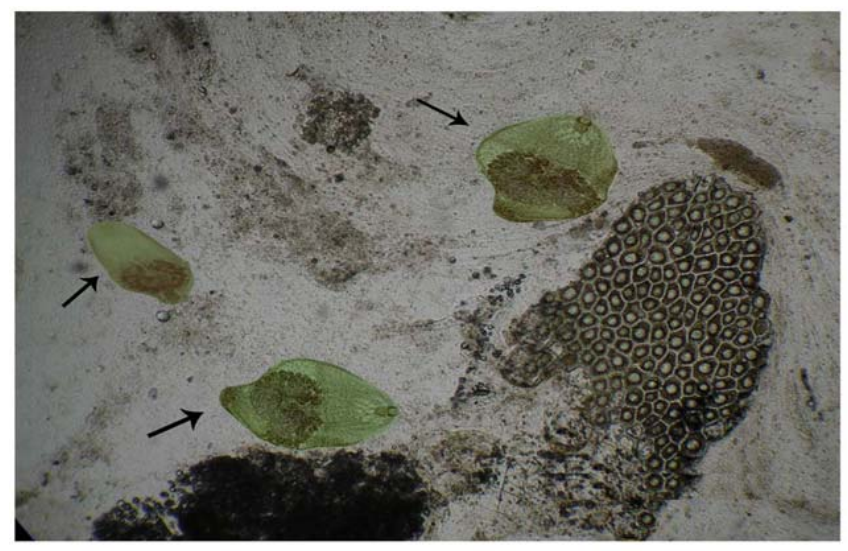

Figure 3: Prohemistomatid worms isolated from feces treated puppies with Moringa oleifera $(x 100)$

\section{Discussion}

The present study revealed that out of examined fresh water fishes 147 were found to be infected by EMC with total infection rate $73.5 \%$. the highest incidence of EMC was recorded in Clarias gariepinus $86 \%$, while in Cyprinus carpio was $61 \%$. The incidence rate of EMC in Clarias gariepinus nearly agrees with AbouEisha et al. (2008) in Ismalia, Saleh et al. (2009) in Port Said, El-Gayar and Aly (2013) in Sharkia and Saba (2014) in Giza reported that $87 \%, 87.1 \%, 87 \%$ and $85.3 \%$ respectively. But it was higher than that reported by El-Gohary and Samaha (1997) in Alexandria was $68 \%$. Dealing the incidence rate of EMC in Cyprinus carpio was higher than recorded by Aly et al. (1995) in Suez canal area and Saba (2004) in Sharkia were $15 \%$ and $50.4 \%$, respectively. But it was lower than that reported by Abou Eisha et al. (2008) in Ismalia and Saleh et al. (2009) in Port Said were $73.4 \%$ and $78.2 \%$ respectively. The high incidence of EMC in Clarias gariepinus may be attributed to their thin skin and soft 

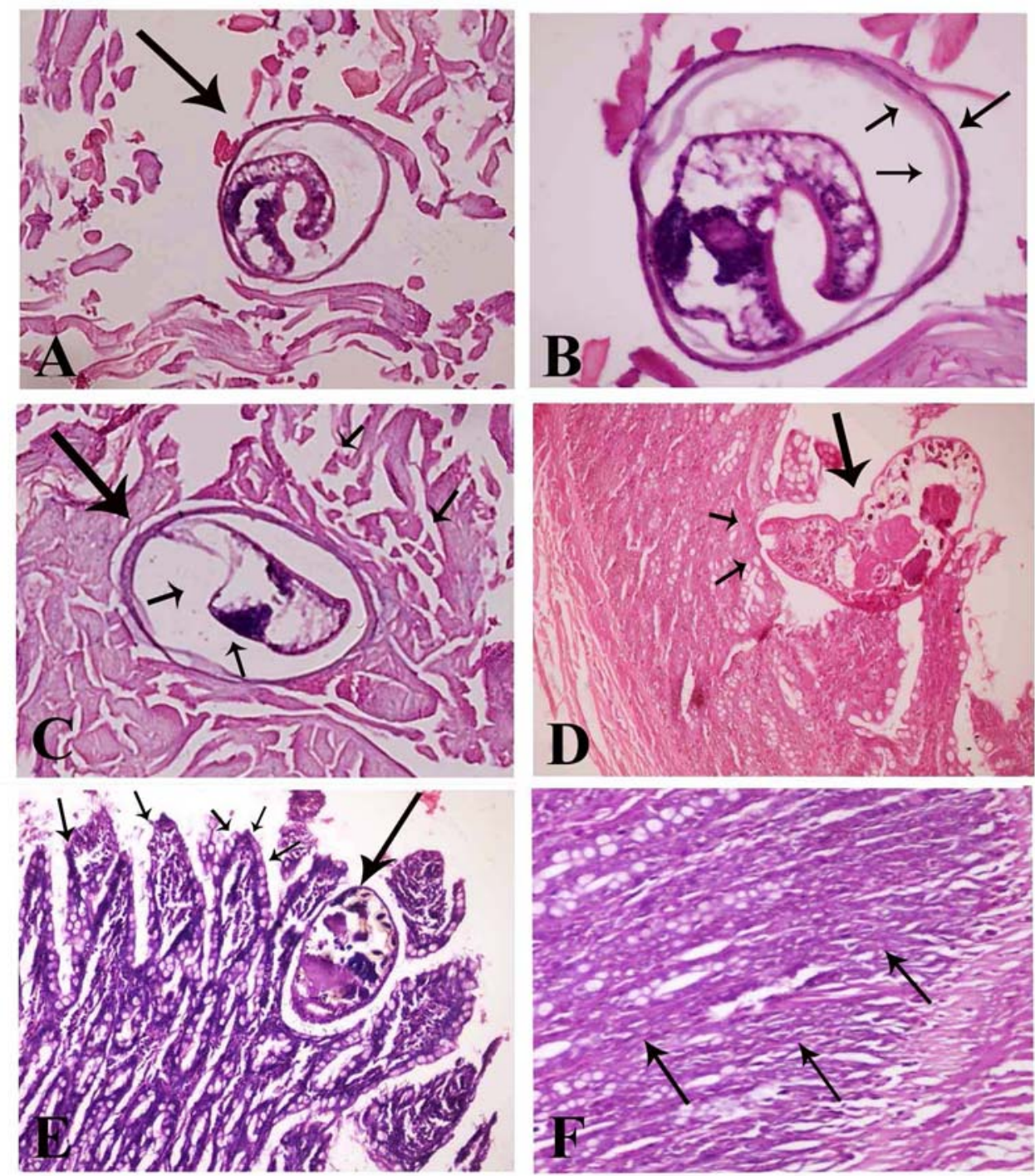

Figure 4: A, B \& C: Cross section of infected fish muscle with EMC. H \& E stain (A, C x100 \& B x200), D \& E: Cross section in intestine of experimental infected puppies with fish born zoonotic trematodes. H \& E stain (D x200 \& E x100), F: Cross section in intestine of treated puppies with Moringa oleifera $(\mathrm{x} 200)$

muscles which probably help in penetration of cercariae, also that the habitat of fishes helped their infection, which feeding on vegetation, where the first intermediate host "snails" is found giving a suitable chance to liberated cercariae to penetrate their skin, while in Cyprinus carpio low percentage $(61 \%)$ that may due to fishes living far away from the river banks and at varying depths probably have escaped from infection with metacercariae, also the thick skin of the fish probably had reduced the penetration capacity of cercariae. In addition to other various factors, including the locality from which fish were caught and the degree of water pollution. It was difficult to confirm the identification of the different kinds of microscopic metacercariae when they were encysted in fish or after isolation (Noga, 2000). For this reason the microscopic metacercariae collected from various parts of examining fish and on the basis of differences in size and morphological characters as well as identification of adult worms yielded after puppies feeding experiment to obtain the accurate typing of these EMC. In the present study, two groups of EMC were identified, the EMC belong to prohemistomatid in Clarias gariepinus, while Cyprinus carpio harboured EMC of heterophyid. From the present experimental work showed that two adult digenetic trematodes of prohemistomatid sp. were recovered from the small intestine of experimentally infected puppies with EMC from Clarias gariepinus including Prohemistomum vivax and Mesostephanus appendiculatus, The morphological features of obtained trematodes are similar with that were described in several studies by Bazh (2003), Saba (2004), AbouEisha et al. (2008), Saleh et al. (2009), El- Gayar and Aly (2013), Hamouda (2014) and El-Azazy et al. (2015). The detected Prohemistomum vivax is transmissible to man (Khalifa et al., 1977; Taher, 2009). 
Two adult heterphyid trematodes were collected from the small intestine of experimentally infected puppies with EMC from Cyprinus carpio included Heterophyes heterophyes and Procervim varium. Heterophyes heterophyes was identical with description of Salem et al. (2010). Procervim varium description was agreed with Chai et al. (2013) from cats with some differences in the measurements. Heterophyiasis is considered a zoonotic problem in Egypt which may be asymptomatic or present with diarrhea and abdominal pain (Salem et al., 2010). Also, death has been reported from cardiac and central nervous system complications especially in immunosuppressed cases where infection is fulminant. Such potential complication emphasizes the importance of early treatment of heterophyiasis (El-Kowrany et al., 1996).

The current study supports and validates anthelmintic activity of Moringa oleifera leaf extract and Moringa oleifera seed oil was investigated through an experimental study on different parameters of examinations. Egg count is an index exploring the intensity of infection and as a parameter for cure (Hall, 1982). It can be utilized both experimentally and clinically in determining the effectiveness of the treatment by making counts both before and after drugs have been given (Jain, 2002). Regarding the mean of egg count per gram (EPG) was found to be lower in puppies treated with Moringa oleifera more than control positive one in the 1st day post treatment. The mean of (EPG) was significantly decreased in puppies treated with Moringa oleifera seed oil than Moringa oleifera leaf extract treated group. At $9^{\text {th }}$ and 7th days of treated with Moringa oleifera leaf extract and Moringa oleifera seed oil groups, respectively. While there was complete disappearance of eggs in feces at the 9thand 7th days after treated of treated puppies with Moringa oleifera leaf extract and Moringa oleifera seed oil, respectively.

Concern worm count recovered from the small intestine (WRR) there were significantly lower WRR in each groups treated with Moringa oleifera leaf extract and Moringa oleifera seed oil than control +ve one. Moringa oleifera seed oil showed higher efficacy than Moringa oleifera leaf extract. As it has a high eradication rate of adult worms from the intestines.

The present results agree with that recorded by Alghabban (2014) from treated rats with the Moringa oleifera leaf extract with some differences in duration of reduction of egg count or recovery rate and adult worm in feces, which may be attributed to differences of experimental hosts were studied and host resistance. Also the obtained results concid with Tabassam et al. (2014) who mentioned that the extracts of Moringa oleifera plants have anthelmintic activity through paralysis of helminthes. It is observed that $M$. oleifera is having a potent anthelmintic activity and its gum is being used as an anti-filarial agent (Kushwaha et al., 2011).

The recorded histopathological alterations in infected fish muscle could be due to embedding of the EMC in the affected muscle fibers that resulted in a pressure atrophy, marked degeneration, focal necrosis and proliferation of the melanomacrophages. The aggregation of melanomacrophages indicated the activated body defense and provides an explanation for the black spots observed grossly on the skin of infected fish. The degenerative changes observed in the affected muscles could be due to the toxic product substance produced by the parasitic cysts. Similar observations were previously recorded by Kotb et al. (2014) and Khalil et al. (2014).

The histopathological changes in puppies's intestine infected experimentally by isolating EMC from examining fish were included villous atrophy, crypt hyperplasia and an increase in number of goblet cells. These reactions attributed to the immune response against the worm infection. Mature worm was demonstrated free in the intestinal lumen or attached to the intestinal wall. The presence of erosions and exfoliation of the epithelial lining might reflect a direct mechanical effect of the parasite. The tissue reaction characterization of acute inflammatory reaction, which including hypercellularity of the lamina propria by various types of cells as lymphocytes, macrophages, plasma cells, eosinophils and neutrophils. These reactions could be attributed to irritation of parasites and their toxic products. This coincides with that mentioned by Mahdy and Shaheed (2001) and Ashour et al. (2014). The duodenal section on treated puppies with Moringa oleifera shows near normal histological structure, with only a few mild villi atrophy with an increased in goblet cell numbers. This result agrees with Alghabban (2014) and Thilza et al. (2010) reported that the Moringa oleifera leaf extract acts as anti -helminthic activity, antimicrobial activity, detoxifier, immune booster and antiparasitic activity. 
By comparative validation of Moringa oleifera derivatives efficacy as anthelmintic agent, the result of the present study proved that Moringa oleifera seed oil has higher anthelmintic activity than Moringa oleifera leaf extract, this may be attributed to the variable concentration of chemical constituents of different examined Moringa oleifera derivatives. This result agrees with Nilani et al. (2012) who sustain the high anthelmintic property of Moringa oleifera seed oil, whereas he clarify that oleic acid was contributing to the traditionally claimed anthelmintic activity, which was present with higher level in the seed oil than in the leaf extract of Moringa oleifera.

\section{Conclusion}

Summing up, data from the present study confirm the higher frequency of EMC in Clarias gariepinus than in Cyprinus carpio. Moreover, the success of obtaining these trematodes experimentally, reflects the health hazard which caused by freshwater fishes if it ingested raw or insufficiently cooked. As the treatment of infected individuals considered one of most effective control strategies against the infection by fish born zoonotic trematodes (FBZTs). The present study focused on validation of the anthelmintic activity of Moringa oleifera derivatives. From results achieved, it can suggest that Moringa oleifera seed oil has high efficacy more than Moringa oleifera leaf extract. But further investigation should try to explore the details of Moringa oleifera on logical, scientific evidence to provide guideline for its medical use for exterminate of intestinal helminthes.

\section{Acknowledgement}

I'm grateful to Dr. Nasser Fadel from Pathology Department, Animal Health Research Institute, Dokki, for his help in pathological examination of the present work.

\section{REFERENCES}

Abou-Eisha, A.M.; Saleh, R.E.; Fadel, H.M.; Youssef, E.M. and Helmy, Y.A. (2008): Role of freshwater fishes in the epidemiology of some zoonotic trematodes in Ismailia province. SCVMJ, XIII (2), pp. 653-676.

Alghabban, A.J.M. (2014): Fish Farms as a source for parasites transport: Parasitological and developmental studies of Prohemistomumvivax with the ameliorating role of Moringaoleifera in the treatment. J. of American Science; 10 (4).

Aly, S., Mayberry, L., El-Melegy, A. and El-Gawady, H. (1995): Pathological studies on parasitic infections in Common Carp. Egypt. J. Comp. Pathol. And Clin. Pathol. 8 (2): $123-130$.
Ammar, A.I. M. (2007): Histopathological Studies on Experimental Heterophyiasis with Evaluation of Therapeutic Effect of Mirazidand Propolis (a natural bee product). M.Sc. Thesis, Parasitology, Faculty of Medicine, Menoufiya University.

Ashour, D.S., Othman, A.A. and Radi, D.A. (2014): Insights into regulatory molecules of intestinal epithelial cell turnover during experimental infection by Heterophyes heterophyes. Exp Parasitol. Aug; 143: 48-54.

Bancroft, J.D. and Gamble, M. (2013): Theory and practice of histological techniques. 7 Edition, Churchill Livingstone, Edinburgh, London, Melbourne and New York, pp: 252.

Bazh, E.K. (2003): Epidemiological studies on some fishborne parasites. M.V.Sc. Thesis (parasitology), Tanta Univ. Chai, J.Y., Bahk, Y. Y. and Sohn, W.M. (2013): Trematodes Recovered in the Small Intestine of Stray Cats in the Republic of Korea. Korean J Parasitol 51(1):99-106.

Chandrashekar, K.S., Thakur, A. and Prasanna, K.S. (2010): Anti-Inflammatory Activity of Moringaoleifera Stem Back Extracts against Carrageenen Induced Rat Paw Edema. Journal of Chemical and Pharmaceutical Research, 2,179-181.

El-Azazy, O.M.E., Abdou, N.M.I., Khalil, A.I., Al-Batel, M.K., Majeed, Q.A.H., Henedi, A.A. and Tahrani, L.M.A. (2015): Potential Zoonotic Trematodes Recovered in Stray Cats from Kuwait Municipality, Kuwait. Korean J Parasitol 53(3):279-287.

El-Gayar, A.K. and Aly, S.M. (2013): Studies on Some Protozoan parasites and Encysted metacercarial Infection of Freshwater Fishes in Egypt. EVMSP J. 11:31-43.

El-gohary, A.H. and Samaha, I.A. (1997): Oreochromis spp. and Clariaslazera as a some of transmitting encysted metacercaria to man. AJAS. vol.10, No. 4: 439-443.

El-Kowrany, S.E.; Abd-El-Ghaffar, A.E. and Ghoraba, H.M. (1996): Experimental heterophyiasis. The effect of immunosuppression on the course of the disease. Egypt. J. Med. Sci., 17(2): 481-497.

Elsheikha, H.M. and Elshazly, A.M. (2008a): Hostdependent variations in the seasonal prevalence and intensity of heterophyid encysted metacercariae (Digenea: Heterophyidea) in brackish water fish in Egypt .Vet. Parasitol., 153: 65-72.

Faust, E.C., Russel, P.F. and June, R.C. (1976): Caring and Faust's clinical parasitology, 8th Ed., Lea and Febger, Philadelhia.

Hall, A. (1982): Intestinal helminthes of man: The interpretation of eggcounts. Parasitol., 85: 605-613.

Hamouda, A. H. S. (2014): Studies on The Trematodal and Cestodal Diseases in Cultured Freshwater Fish in Kafr ElSheikh Governorate. Ph.D. Thesis, fish diseases and management, Fac. Vet. Med. Kafrelsheikh Univ.

Jain, P.C. (2002): General Veterinary Parasitology. 1st edition, Jaypee Brothers Medical Publishers LTD, P: 62-63. Janani, R.P., Subhaharshni, R. and Poongothai, K. (2013): Anthelmintic activity of leaf extracts of Moringa oleifera 
and annona squamosa against gastrointestinal nematodes of goats. International Journal of Future Biotechnology 2 (2), 1-9.

Kamaraj, C. and Abdul Rahuman, A. (2011): Efficacy of Anthelmintic Properties of Medicinal Plant Extracts against Haemonchus contortus. Research on Veterinary Science, 91, 400-404.

Khalifa, R, El-Naffar, M.K., Arafa MS. (1977): Studies on heterophid cercariae from Assiut Province. 1- Notes on the life cycle of Haplorchis pumilio (Looss, 1896) Trematoda: Heterophyidae) with a discussion on previously described forms. Actaparasitol. Polonica, 25 (3): 25: 38.

Khalil, M.I., El-Shahawy, I.S. and Abdelkader, H. S. (2014): Studies on some fish parasites of public health importance in the southern area of Saudi Arabia. Braz. J. Vet. Parasitol., Jaboticabal, vol. 23, 4, p. 435-442.

Kotb, H.L., Mahdy, O.A. and Shaheed, I.B. (2014): Parasitological and Histopathological Study of Digenetic Trematodes in Mullets from Lake Qarun, Egypt. Global Veterinaria 13(2):202-208.

Kushwaha, V., K. Saxena, S.K. Verma, V. Lakshmi, R.K. Sharma and P.K. Murthy, (2011): Antifilarial activity of gum from Moringa oleifera Lam. On human lymphatic filaria Brugiamalayi. Chron. Young Scientists 2(4):201-206.

Mahdy, O.A. and Shaheed, I.B. (2001): Studies on the metacercarial infection among Tilapia species in Egypt. Helminthologia, 38, 1:35-42.

Mbikay, M. (2012): Therapeutic Potential of Moringa oleifera Leaves in Chronic Hyperglycemia and Dyslipidemia: A Review. Frontiers in Pharmacology, 3:137.

Nilani, P., Mani Kumar Pinaka, Duraisamy B., Dhamodaran, P. and Jeyaprakash, M.R. (2012): Anthelmintic Activity of Moringa Oleifera Seed Oil Validation of Traditional Use J Adv Scient Res, 3(2): 65-66. Nithikathkul, C. and Wongsawad, C. (2008): Prevalence of Haplorchis taichui and Haplorchoides sp. Metacercariae in freshwater fish from water reservoirs, Chiang Mai, Thailand. Korean journal of Parasitology, 46(2):109-112.

Noga, E.N. (2000): Fish diseases (diagnosis and treatment) Blackwell Science Ltd.,U.S.A. 378 pp.

Oczkowski, A. J., Nixon, S. W., Granger, S. L., El-Sayed, A. F., McKinney, R. A. (2009): Anthropogenic enhancement of Egypt's Mediterranean fishery. Proc Natl. Acad Sci USA; 106:1364-1367.

Saba, S.E.R. (2004): Some studies on parasites encystations of fresh water fishes. Ph.D. Thesis, Parasitology, Fac. Vet. Med. Zagazig. Univ.
Saba, S.E.R. (2014): Level of Infection of Some Freshwater Fishes with Encysted Metacercariae With Relation To Its Public Health. 6th. Sc. Con. of EVMSP J. Vol. 10, pp.127140.

Saleh, R. S., Abou-Eisha, A. M., Fadel, H.M. and Helmy, Y. A. (2009): occurrence of encysted metacercariae of some Zoonotic trematodes in freshwater fishes and their Public health significance in port said province. Abbassa International Journal for Aquaculture, ISSN 1687-7683, Special Issue for Global Fisheries \& Aquaculture Research Conference, Cairo International Convention Center, pp 341 $-351$.

Salem, L.M., Metawea, Y. and El-sheikha, H. (2010): Prevalence of heterophyiosis in Tilapia fish and in humans in Northern Egypt. Parasitology Research, 107(4):1029-34. Singh, N., Verna, V.K., Saxena, P. and Singh, R. (2012): Anti-Ulcer and Antioxidant Activity of Moringaoleifera (Lam) Leaves against Aspirin and Ethanol Induced Gastric Ulcer in Rats. International Research Journal of Pharmaceuticals, 2:46-57.

Sohn, W.M and Chai, J.Y. (2005): Infection status with helminthes in feral cats purchased from a market in Busan, Republic of Korea. Korean J Parasitol; 43: 93-100.

Sohn, W.M.; Eom, K.; Min, D.Y.; Rim, H.J.; Hoang, E.H.; Yang, Y. and Li, X. (2009): Fish-borne Trematode Metacercariae in Freshwater Fish from Guangxi Zhuang Autonomous Region, China. Korean J. Parasitol. 47(3):249257.

Tabassam, F., Muhammad, S.S., Muhammad, J.H., Rao, M. S. and Zafar, I. (2014): Phytomedicinal value of moringaoleifera with special reference to antiparasitics. Pak. J. Agri. Sci., Vol. 51(1), 251-262.

Taher, G.A. (2009): Some studies on metacercarial infection in Oreochromis niloticus in Assiut governorate and their role in transmission of some trematodes to dogs. Ass. Univ. Bull. Environ. Res., 12: 1.

Thilza, I., Sanni, S., Zakari, A., Muhammed, T. and Musa, B. (2010): In vitro antimicrobial of water extract of Moringaoleifera leaf stalk on bacterial normally implicated in eye disease. Acad. Aren.; 2:80-83.

World Health Organization. WHO (1995): Control of foodborne trematodes infections. Geneva; 1-107.

World Health Organization WHO (2011): Report of the WHO expert consultation on foodborne trematode infections and taeniasis/cysticercosis, Vientiane, Lao People's Democratic Republic. WHO Press, Geneva.

Yamaguti, S. (1958): Systema helminthes of fish. Vol 1. Digentic Trematodes of the vertebrates part 1 and 2, Inter science publishers, Inc. New York. 